\title{
SOLUSI ASIMTOTIK PADA PERSAMAAN DIFUSI DENGAN WAKTU SINGKAT
}

\author{
DILLA OKTAVIA \\ Jurusan Matematika, \\ Fakultas Matematika dan Ilmu Pengetahuan Alam, Universitas Andalas, \\ Kampus UNAND Limau Manis Padang, Indonesia. \\ email : oktavia_dilla@yahoo.com
}

\begin{abstract}
Abstrak. Pada makalah ini akan ditentukan solusi asimtotik dari persamaan difusi dengan waktu singkat pada kasus satu dimensi. Untuk mengatasi syarat awal yang takkontinu loncat di $x=0$, digunakan metode pencocokan asimtotik (asymptotic matching) yang dianalisis pada tiga daerah yang berbeda, yaitu daerah I $(x<0)$, daerah II $(x>0)$, dan daerah III $(|x| \ll 1)$. Hasil yang diperoleh dapat menjelaskan bagaimana perilaku solusi sesaat setelah kondisi awal mulai berdifusi.
\end{abstract}

Kata Kunci: Solusi asimtotik, persamaan difusi, pencocokan asimtotik

\section{Pendahuluan}

Persamaan diferensial adalah persamaan yang memuat turunan suatu fungsi yang tak diketahui. Persamaan diferensial yang memuat turunan parsial disebut persamaan diferensial parsial (PDP). Salah satu fenomena yang dapat dimodelkan secara matematis dengan persamaan diferensial parsial terdapat pada bidang kimia fisik. Model matematika yang sering ditemui dalam bidang kimia fisik adalah persamaan difusi yang menjelaskan perubahan konsentrasi dari suatu zat kimia. Persamaan difusi adalah persamaan diferensial parsial yang merepresentasikan berpindahnya suatu zat dalam pelarut dari bagian berkonsentrasi tinggi ke bagian yang berkonsentrasi rendah.

Persamaan difusi diperkenalkan pada tahun 1855 oleh Adolf Fick, seorang fisikawan Jerman [1]. Secara umum, persamaan difusi dapat diselesaikan dengan transformasi Laplace atau Fourier. Namun, hasilnya muncul dalam bentuk integral konvolusi yang tidak dapat memberikan profil solusi secara jelas. Untuk mengatasi hal tersebut, metode perturbasi dapat digunakan untuk melihat perubahan profil solusi yang terjadi terhadap suatu parameter yang bernilai kecil (disebut parameter perturbasi). Solusi yang dihasilkan dari metode ini dikenal sebagai solusi asimtotik.

Pada makalah ini akan ditentukan solusi asimtotik dari persamaan difusi dengan parameter perturbasi berupa waktu singkat $(t \ll 1)$ dan syarat awal tak-kontinu loncat sehingga dapat diketahui prilaku solusi sesaat setelah kondisi awal mulai berdifusi. Solusi yang dihasilkan pada kasus ini juga dikenal sebagai solusi waktu singkat (small time solution). Pada kasus ini, penyelesaian persamaan tersebut tidak dapat lagi dilakukan dengan menggunakan metode pertubasi biasa karena adanya syarat awal yang tak-kontinu loncat. Untuk mengatasi hal ini, digunakan metode 
pencocokan asimtotik (asymptotic matching). Kajian pada makalah ini mengeksplorasi kembali pembahasan pada referensi [4].

\section{Penurunan Persamaan Difusi}

Pada bagian ini akan dibahas penurunan persamaan difusi yang merujuk dari referensi [5]. Pandang suatu pipa panjang yang berisi air yang tidak mengalir yang terkontaminasi oleh suatu polutan pada bagian kecil pipa yang disebabkan oleh kebocoran pada pipa (lihat Gambar 1.

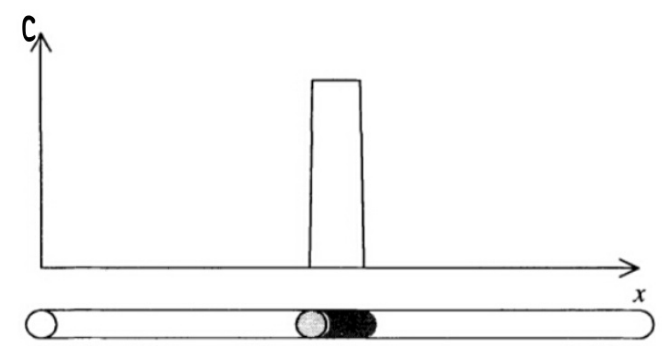

Gambar 1. Profil konsentrasi polutan $c(x, t)$ pada suatu pipa air

Misalkan $c(x, t)$ adalah konsentrasi (massa per satuan panjang) dari polutan pada posisi $x$ dan waktu $t$ dan $\phi(x, t)$ menyatakan fungsi fluks, yaitu laju (massa per satuan waktu) dimana polutan melewati posisi $x$ dan waktu $t$. Berdasarkan Hukum Konservasi [5], maka berlaku

$$
\frac{\partial}{\partial t} c(x, t)+\frac{\partial}{\partial x} \phi(x, t)=f(x, t)
$$

dengan $f(x, t)$ menyatakan fungsi sumber, yaitu laju (massa per satuan panjang) dimana polutan masuk ke atau keluar dari pipa pada posisi $x$ dan waktu $t$. Karena air dalam pipa tidak mengalir, maka polutan dapat mengalir melalui air adalah dengan cara difusi. Secara umum, polutan akan mengalir dari daerah dengan konsentrasi tinggi ke daerah dengan konsentrasi rendah agar dapat menyebar secara merata.

Sebagai contoh, misalkan konsentrasi $c(x, t)$ di sepanjang pipa pada waktu $t$ memiliki profil yang ditunjukkan pada Gambar 2. Jika $x$ menyatakan posisi polutan dengan kemiringan, $\frac{\partial}{\partial x} c(x, t)$ positif, maka polutan mengalir ke kiri menuju daerah dengan konsentrasi rendah. Sebaliknya, jika kemiringan, $\frac{\partial}{\partial x} c(x, t)$ negatif, maka polutan mengalir ke kanan. Fenomena ini menjadi dasar dari Hukum Difusi Pertama Fick [5], yaitu

$$
\phi(x, t)=-D \frac{\partial}{\partial x} c(x, t)
$$




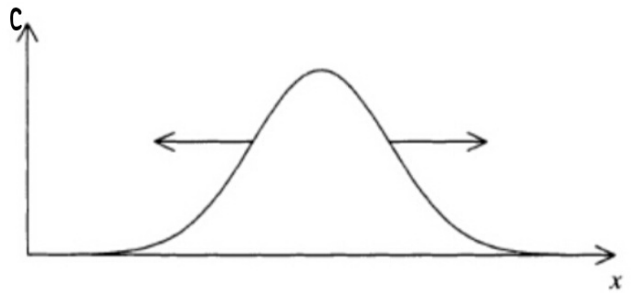

Gambar 2. Arus polutan dari daerah yang memiliki konsentrasi lebih ke tinggi konsentrasi yang lebih rendah

dengan $D$ adalah konstanta positif, dan tanda negatif (-) menunjukkan bahwa arah aliran berlawanan dengan tanda dari kemiringan $\frac{\partial}{\partial x} c(x, t)$.

Jika diasumsikan kebocoran pada pipa telah diperbaiki sehingga tidak ada polutan tambahan yang masuk ke dalam pipa dan tidak terjadi penyaringan atau reaksi kimia yang menghilangkan polutan, maka $f(x, t)=0$. Selanjutnya dari persamaan (2.2) diperoleh $\phi_{x}(x, t)=-D \frac{\partial^{2}}{\partial x^{2}} c(x, t)$. Dengan demikian Hukum Konservasi (2.1) menjadi persamaan difusi

$$
\frac{\partial}{\partial t} c(x, t)-D \frac{\partial^{2}}{\partial x^{2}} c(x, t)=0 .
$$

\section{Analisis Asimtotik pada Persamaan Difusi}

Pada bagian ini akan dibahas tentang solusi asimtotik dari persamaan difusi untuk kasus waktu singkat $(t \ll 1)$ dengan syarat awal tak-kontinu loncat. Masalah nilai awal untuk persamaan difusi ini diberikan oleh:

$$
\frac{\partial}{\partial t} c(x, t)=D \frac{\partial^{2}}{\partial x^{2}} c(x, t), \text { untuk }-\infty<x<\infty \text { dan } t>0,
$$

dengan $c(x, t)$ adalah distribusi panas atau konsentrasi bahan kimia pada posisi $x$ dan waktu $t$, dan $D$ adalah koefisien difusi, dengan syarat awal

$$
c(x, 0)= \begin{cases}f_{0}(x) & , x \leq 0 \\ 0, & x>0\end{cases}
$$

dengan $f_{0}$ adalah fungsi yang turunan pertama dan turunan keduanya kontinu, $f_{0} \rightarrow 0$ bilamana $x \rightarrow-\infty, f_{0}(0) \neq 0$ dan

$$
\int_{-\infty}^{0} f_{0}(x) d x=f_{\text {tot }}
$$

Persamaan (3.1) dapat diselesaikan dengan menggunakan transformasi Laplace atau Fourier. Namun, hasilnya muncul dalam bentuk integral konvolusi yang tidak dapat memberikan profil solusi secara jelas. Agar dapat dipelajari prilaku solusi sesaat setelah kondisi awal mulai berdifusi, maka akan ditinjau solusi asimtotik dari persamaan $(3.1)$ untuk kasus waktu singkat $(t \ll 1)$. Akan ditinjau tiga daerah yang berbeda, yaitu: 
(1) Daerah I: $x<0$.

Pada daerah ini terjadi pemulusan konsentrasi awal secara bertahap.

(2) Daerah II: $|x| \ll 1$.

Ciri utama pada daerah ini adalah pemulusan seketika dari ketak-kontinuan loncat konsentrasi awal.

(3) Daerah III: $x>0$.

Terdapat fluks dari $x<0$ ke daerah ini, sehingga diperkirakan terjadi perubahan langsung dari $c(x, t)=0$ menjadi $c(x, t) \neq 0$.

\subsection{Analisis di Daerah I dan III}

Bentuk ekspansi untuk $t \ll 1$ sebagai berikut:

$$
c(x, t)=f_{0}(x)+t f_{1}(x)+t^{2} f_{2}(x)+\mathcal{O}\left(t^{3}\right) .
$$

Perhatikan bahwa

$$
\begin{aligned}
\frac{\partial}{\partial t} c(x, t) & =f_{1}(x)+2 t f_{2}(x)+3 t^{2} f_{3}(x)+\cdots, \\
\frac{\partial^{2}}{\partial x^{2}} c(x, t) & =f_{0}^{\prime \prime}(x)+t f_{1}^{\prime \prime}(x)+t^{2} f_{2}^{\prime \prime}(x)+\cdots .
\end{aligned}
$$

Substitusi persamaan (3.5) dan persamaan (3.6) ke persamaan (3.1), maka diperoleh

$$
f_{1}(x)-D f_{0}^{\prime \prime}(x)+t\left(2 f_{2}(x)-D f_{1}^{\prime \prime}(x)\right)+\mathcal{O}\left(t^{2}\right)=0 .
$$

Dengan demikian pada saat $\mathcal{O}(1)$ diperoleh persamaan

$$
f_{1}(x)=D f_{0}^{\prime \prime}(x)
$$

dan pada saat $\mathcal{O}(t)$ diperoleh persamaan

$$
2 f_{2}(x)=D f_{1}^{\prime \prime}(x)
$$

Dengan demikian,

$$
c(x, t)=f_{0}(x)+t D f_{0}^{\prime \prime}(x)+\frac{1}{2} t^{2} D^{2} f_{0}^{(4)}(x)+\mathcal{O}\left(t^{3}\right) .
$$

Perhatikan bahwa $c(x, t)$ meningkat pada daerah dimana $f_{0}^{\prime \prime}>0$, dan sebaliknya. Perhatikan juga bahwa bilamana $x \rightarrow 0^{-}$maka $c(x, t) \sim f_{0}(0)$. Namun pada $x>0$, $c(x, t)$ diharapkan bernilai kecil dan solusi di daerah I dan III tidak akan cocok (match) tanpa adanya lapisan batas yang berpusat di titik asal, yaitu di daerah daerah II [2].

Sebelum menentukan lapisan batas tersebut, ditentukan terlebih dahulu solusi di daerah III, dimana $c(x, t)$ bernilai kecil. Dengan menggunakan ekspansi WKB [2] sampai $\mathcal{O}(t)$ dalam bentuk

$$
c(x, t)=e^{-\frac{A(x)}{t}+B(x) \ln t+C(x)},
$$

maka diperoleh

$$
\frac{\partial}{\partial t} c(x, t)=\left(\frac{A(x)}{t^{2}}+\frac{B(x)}{t}\right) e^{-\frac{A(x)}{t}+B(x) \ln t+C(x)},
$$


dan

$$
\begin{aligned}
\frac{\partial^{2}}{\partial x^{2}} c(x, t)= & \left(-\frac{A_{x}^{2}}{t^{2}}+\left(-\frac{A_{x x}}{t}-2 \frac{A_{x} C_{x}}{t}\right)+\left(B_{x x} \ln t+2 B_{x} C_{x} \ln t\right)-2 \frac{A_{x} B_{x} \ln t}{t}\right. \\
& \left.+\left(B_{x} \ln t\right)^{2}+C_{x x}+C_{x}^{2}\right) e^{-\frac{A(x)}{t}+B(x) \ln t+C(x)}
\end{aligned}
$$

Substitusi persamaan (3.12) dan (3.13) ke persamaan (3.1), maka diperoleh

$$
\begin{aligned}
0= & \frac{1}{t^{2}}\left(-A+D A_{x}^{2}\right)+\frac{1}{t}\left(-B+D\left(-A_{x x}-2 A_{x} C_{x}\right)\right)+\frac{\ln t}{t} D\left(2 A_{x} B_{x}\right) \\
& +D\left(B_{x} \ln t\right)^{2}-\ln t\left(2 B_{x} C_{x}\right)-\ln t D\left(B_{x x}+2 B_{x} C_{x}\right)+D\left(C_{x x}+C_{x^{2}}\right) .
\end{aligned}
$$

Selanjutnya akan dianalisis persamaan di masing-masing orde.

(1) Pada saat $\mathcal{O}\left(\frac{1}{t^{2}}\right)$ diperoleh

$$
A(x)=\frac{x^{2}}{4 D}+\beta x+D \beta^{2} .
$$

dengan $\beta$ adalah suatu konstanta integrasi.

(2) Pada saat $\mathcal{O}\left(\frac{\ln t}{t}\right)$ diperoleh

$$
B(x)=b,
$$

dengan $b$ adalah suatu konstanta.

(3) Pada saat $\mathcal{O}\left(\frac{1}{t}\right)$ diperoleh

$$
C(x)=-\left(b+\frac{1}{2}\right) \ln (x+2 \beta D)+d,
$$

dengan $d$ adalah suatu konstanta.

Solusi WKB di daerah III sampai $\mathcal{O}(t)$ diperoleh dengan mensubsitusikan persamaan (3.15), (3.16), dan persamaan (3.17) ke dalam persamaan (3.11), yaitu

$$
c(x, t)=\exp \left(-\frac{1}{t}\left(\frac{x^{2}}{4 D}+\beta x+D \beta^{2}\right)+b \ln t-\left(b+\frac{1}{2}\right) \ln (x+2 \beta D)+d\right) .
$$

\subsection{Analisis di Daerah II}

Pada lapisan batas (daerah II), lakukan skala ulang $\eta=\frac{x}{t^{\alpha}}$, dengan $t \ll 1,|\eta|=$ $\mathcal{O}(1), \alpha>0$ akan ditentukan, dan $c(x, t)=C(\eta, t)$.

Dengan menggunakan aturan rantai untuk turunan parsial, diperoleh

$$
\begin{aligned}
\frac{\partial}{\partial t} c(x, t) & =\frac{\partial}{\partial t} C(\eta, t)=-\frac{\alpha}{t} \eta \frac{\partial}{\partial \eta} C(\eta, t)+\frac{\partial}{\partial t} C(\eta, t), \\
\frac{\partial^{2}}{\partial x^{2}} c(x, t) & =\frac{\partial^{2}}{\partial x^{2}} C(\eta, t)=\frac{1}{t^{2 \alpha}} \frac{\partial^{2}}{\partial \eta^{2}} C(\eta, t) .
\end{aligned}
$$


Dengan mensubstitusikan persamaan (3.19) dan persamaan (3.20) ke persamaan (3.1) diperoleh

$$
\frac{\partial}{\partial t} C(\eta, t)-\frac{\alpha}{t} \eta \frac{\partial}{\partial \eta} C(\eta, t)=D \frac{1}{t^{2 \alpha}} \frac{\partial^{2}}{\partial \eta^{2}} C(\eta, t) .
$$

Karena $C(\eta, t)=\mathcal{O}(1)$ pada lapisan batas (perhatikan bahwa $C(\eta, t)$ harus cocok dengan solusi di daerah I bilamana $\eta \rightarrow-\infty$, dengan $C(\eta, t)=\mathcal{O}(1))$, maka balance yang mungkin adalah antara suku kedua dan ketiga pada persamaan (3.21), yaitu

$$
t^{-1}=t^{-2 \alpha} \quad \Leftrightarrow \quad \alpha=1 / 2
$$

Dengan demikian persamaan (3.21) menjadi

$$
\frac{\partial}{\partial t} C(x, t)-\frac{1}{2 t} \eta \frac{\partial}{\partial \eta} C(x, t)=D \frac{1}{t} \frac{\partial^{2}}{\partial \eta^{2}} C(x, t) .
$$

Karena $C(\eta, t)=\mathcal{O}(1)$, maka dapat digunakan ekspansi $C(\eta, t)=C_{0}(\eta)+\mathcal{O}(t)$, sehingga pada saat leading order diperoleh

$$
-\frac{1}{2} \eta \frac{d}{d \eta} C_{0}(\eta)=D \frac{d^{2}}{d \eta^{2}} C_{0}(\eta)
$$

Solusi dari persamaan (3.24) diberikan sebagai berikut:

$$
C_{0}(\eta)=F+G \int_{-\infty}^{\eta} e^{-s^{2} / 4 D} d s
$$

\subsection{Pencocokan Asimtotik}

Jika solusi di daerah I dan III, yang masing-masing diberikan oleh persamaan (3.10) dan (3.18), ditulis ulang dalam bentuk $c(x, t)=C(\eta, t)$, dengan $\eta=\frac{x}{\sqrt{t}}$, maka diperoleh

$$
C(\eta, t)=f_{0}(\eta \sqrt{t})+\mathcal{O}(t)
$$

dan

$$
C(\eta, t)=\exp \left(-\frac{\eta^{2}}{4 D}-\frac{\beta \eta}{t^{\frac{1}{2}}}-\frac{D \beta^{2}}{t}+b \ln t-\left(b+\frac{1}{2}\right) \ln \left(\eta t^{\frac{1}{2}}+2 \beta D\right)+d\right)
$$

Karena $C(\eta, t)=C_{0}(\eta)+\mathcal{O}(t)$, maka untuk $t \ll 1$ diperoleh syarat pencocokan pada daerah I dan III sebagai berikut:

$$
C_{0}(\eta) \sim f_{0}(0) \text { bilamana } \eta \rightarrow-\infty,
$$

dan

$$
\begin{aligned}
C_{0}(\eta) \sim & \exp \left(-\frac{D \beta^{2}}{t}-\frac{\beta \eta}{t^{\frac{1}{2}}}-\frac{\eta^{2}}{4 D}+b \ln t-\left(b+\frac{1}{2}\right) \ln \left(\eta t^{\left(\frac{1}{2}\right)}+2 \beta D\right)+d\right) \\
& \text { bilamana } \eta \rightarrow \infty
\end{aligned}
$$


Dari persamaan (3.25) dan (3.28) diperoleh $C_{0}(\eta) \sim F=f_{0}(0)$ bilamana $\eta \rightarrow$ $-\infty$. Selanjutnya bilamana $\eta \rightarrow \infty$, dengan menggunakan pengintegralan parsial dan mengganti $F=f_{0}(0)$, persamaan (3.25) dapat ditulis ulang menjadi

$$
C_{0}(\eta)=f_{0}(0)+G\left(\int_{-\infty}^{\infty} e^{s^{2} / 4 D} d s-\frac{2 D}{\eta} e^{-\eta^{2} / 4 D}+\mathcal{O}\left(\frac{1}{\eta^{2}} e^{-\eta^{2} / 4 D}\right)\right)
$$

Agar persamaan (3.30) konsisten dengan syarat pencocokan (3.27), maka haruslah

$$
f_{0}(0)+G \int_{-\infty}^{\infty} e^{-s^{2} / 4 D} d s=0 .
$$

Diketahui bahwa $\int_{0}^{\infty} e^{-t^{2}} d t=\sqrt{\frac{\pi}{2}}[4]$. Akibatnya $\int_{-\infty}^{\infty} e^{s^{2} / 4 D} d s=\sqrt{4 \pi D}$. Dengan demikian $G=-\frac{f_{0}(0)}{\sqrt{4 \pi D}}$. Oleh karena itu

$$
c(x, t)=C_{0}(\eta) \sim \exp \left\{-\frac{\eta^{2}}{4 D}+\ln (-2 D G)-\ln \eta\right\} .
$$

Agar konsisten dengan syarat pencocokan (3.27), maka mestilah $\beta=0, b=\frac{1}{2}$ dan $d=\ln (-2 D G)$.

Contoh 3.1. Perhatikan masalah nilai awal untuk persamaan difusi berikut:

$$
\frac{\partial}{\partial t} c(x, t)=\frac{\partial^{2}}{\partial x^{2}} c(x, t), \text { untuk }-\infty<x<\infty \text { dan } t>0,
$$

dengan syarat awal

$$
c(x, 0)= \begin{cases}e^{x}, & x \leq 0 \\ 0, & x>0\end{cases}
$$

Perhatikan bahwa $f(x)=e^{x}$ adalah fungsi yang turunan pertama dan turunan keduanya kontinu, $e^{x} \rightarrow 0$ bilamana $x \rightarrow-\infty, e^{0}=1$ dan

$$
\int_{-\infty}^{0} e^{x} d x=1
$$

Dalam contoh ini, koefisien difusi $D=1$. Dengan demikian diperoleh $G=$ $-\frac{f_{0}(0)}{\sqrt{4 \pi D}}=-\frac{e^{0}}{\sqrt{4 \pi}}=-\frac{1}{\sqrt{4 \pi}}$. Berdasarkan persamaan (3.10), solusi untuk daerah I $(x<0)$ diberikan oleh

$$
c(x, t)=e^{x}+t e^{x}+\frac{1}{2} t^{2} e^{x}+\mathcal{O}\left(t^{3}\right) .
$$

Selanjutnya berdasarkan persamaan (3.18) dengan $\beta=0, b=1 / 2$, dan $d=$ $\ln (-2 D G)=\ln \left(-2(1)\left(-\frac{e^{0}}{\sqrt{2 \pi}}\right)\right)=-0,2258$, diperoleh solusi untuk daerah III $(x>0)$ sebagai berikut:

$$
c(x, t) \sim \exp \left(-\frac{x^{2}}{4 t}+\frac{1}{2} \ln t-\ln x-0,2258\right) .
$$


Terakhir, berdasarkan persamaan (3.32) diperoleh solusi untuk daerah II $(|x| \ll 1)$ sebagai berikut:

$$
C_{0}(\eta)=\exp \left(-\frac{\eta^{2}}{4}+\ln \left(-\frac{2}{\sqrt{4 \pi}}\right)-\ln \eta\right) .
$$

Plot ketiga solusi tersebut saat $t=0,1$ dan $t=0,5$ masing-masing diperlihatkan pada Gambar 3 dan 4. Dari gambar Gambar 3 dan 4 dapat dilihat bahwa konsentrasi $c(x, t)$ mengalami proses difusi seiring waktu berjalan.

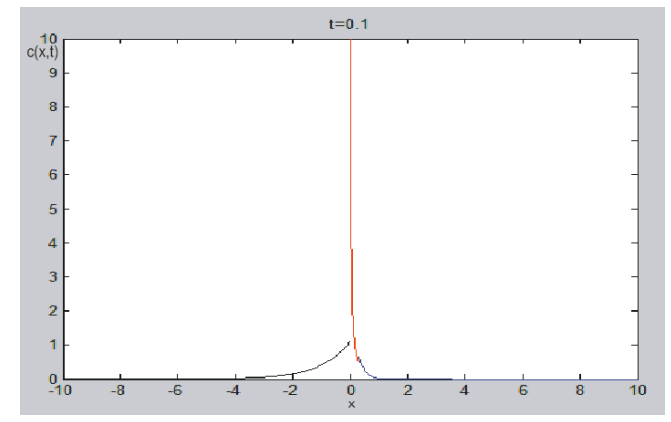

Gambar 3. Plot solusi pada daerah I,II dan III saat $t=0.1$

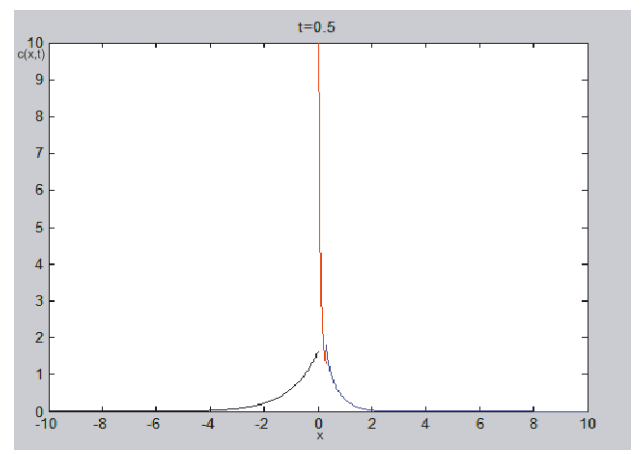

Gambar 4. Plot solusi pada daerah I,II dan III saat $t=0.5$

\section{Kesimpulan}

Pada makalah ini digunakan metode pencocokan asimtotik untuk mencari solusi asimtotik dari persamaan difusi dengan kasus waktu singkat $(t \ll 1)$ yang diberikan oleh

$$
\frac{\partial}{\partial t} c(x, t)=D \frac{\partial^{2}}{\partial x^{2}} c(x, t), \text { untuk }-\infty<x<\infty \text { dan } t>0,
$$


dengan $c(x, t)$ adalah distribusi panas atau konsentrasi bahan kimia pada posisi $x$ dan waktu $t$, dan $D$ adalah koefisien difusi, dengan syarat awal

$$
c(x, 0)= \begin{cases}f_{0}(x), & x \leq 0 \\ 0, & x>0\end{cases}
$$

Solusi asimtotik yang diperoleh adalah sebagai berikut.

(1) Untuk daerah $x<0$ diperoleh solusi asimtotik

$$
c(x, t)=f_{0}(x)+t D f_{0}^{\prime \prime}(x)+\frac{1}{2} t^{2} D^{2} f_{0}^{(4)}(x)+\mathcal{O}\left(t^{3}\right) .
$$

(2) Untuk daerah $x>0$, diperoleh solusi asimtotik

$$
c(x, t)=\exp \left(-\frac{1}{t}\left(\frac{x^{2}}{4 D}+\beta x+D \beta^{2}\right)+b \ln t-\left(b+\frac{1}{2}\right) \ln (x+2 \beta D)+d\right) .
$$

(3) Untuk daerah $|x| \ll 1$ (lapisan batas), diperoleh solusi asimtotik

$$
c(x, t)=C_{0}(\eta) \sim \exp \left\{-\frac{\eta^{2}}{4 D}+\ln (-2 D G)-\ln \eta\right\}, \quad \eta=\frac{x}{\sqrt{t}} .
$$

\section{Ucapan Terima kasih}

Penulis mengucapkan terima kasih kepada Dr. Mahdhivan Syafwan, Dr. Susila Bahri, Drs. Syafruddin, M.Si, Dr. Shelvi Ekariani dan Radhiatul Husna, M.Si yang telah memberikan masukan dan saran sehingga makalah ini dapat diselesaikan dengan baik.

\section{Daftar Pustaka}

[1] Atkins. P. W. 1999. Kimia Fisika. Jilid II. Edisi Keempat. Jakarta: Erlangga.

[2] Boyce, W. E dan Richard, C. D. 2009. Elementary Differential Equations and Boundary Value Problems. Jhon Wiley and Son: New York.

[3] Taneja. H. C. 2008. Advanced Engineering Mathematics. I. K International Publishing House Pvt. Ltd: New Delhi.

[4] King, A. C, J. Bilingham, and S. R. Otto. 2003. Differential Equations: Linear, Ordinary, Partial. Cambridge University Press: Cambridge.

[5] Knobel, R. 2000. An Introduction to the Mathematical Theory of Waves. American Mathematical Society: New York. 